\title{
The tumor-inhibitory effectiveness of a novel anti-Trop2 Fab conjugate in pancreatic cancer
}

\author{
Yuan Mao', Xiaoying Wang, ${ }^{2,3}$, Feng Zheng ${ }^{2}$, Changjun Wang ${ }^{2}$, Qi Tang ${ }^{3}$, Xiaojun \\ Tang $^{3}$, Ning $\mathbf{X u}^{3}$, Huiling Zhang ${ }^{4}$, Dawei Zhang ${ }^{5}$, Lin Xiong ${ }^{6}$, Jie Liang7, Jin Zhu ${ }^{2,3}$ \\ ${ }^{1}$ Department of Oncology, Jiangsu Province Geriatric Hospital, Nanjing 210024, China \\ ${ }^{2}$ Huadong Medical Institute of Biotechniques, Nanjing 210002, China \\ ${ }^{3}$ Department of Pathology and The Key Laboratory of Antibody Technique of Ministry of Health, Nanjing Medical University, \\ Nanjing 210029, China \\ ${ }^{4}$ Department of Gynecology and Obstetrics, Nanjing Maternal and Children Care Hospital Affiliated to Nanjing Medical \\ University, Nanjing 210029, China \\ ${ }^{5}$ Department of Otolaryngology-Head and Neck Surgery, The Second Affiliated Hospital of Nanjing Medical University, Nanjing \\ 210011, China \\ ${ }^{6}$ Department of Pathology, The Second Affiliated Hospital of Nanjing Medical University, Nanjing 210011, China \\ ${ }^{7}$ Department of Pathology, Wuxi Nanjing Maternal and Children Care Hospital Affiliated to Nanjing Medical University, Wuxi \\ 214002, China \\ Correspondence to: Yuan Mao, e-mail: ymaoent@yahoo.com \\ Jin Zhu, e-mail: zhujin1968@njmu.edu.cn
}

Keywords: Trop2, Fab, DOX, ADC, pancreatic carcinoma

Received: January 14, 2016

Accepted: February 28, 2016

Published: April 01, 2016

\section{ABSTRACT}

Human trophoblastic cell surface antigen 2 (Trop2) has been reported to act oncogenically. In this study, one-step quantitative real-time polymerase chain reaction ( PPCR) test and immunohistochemistry (IHC) analysis with were employed to evaluate the relationship between Trop2 expression and the clinicopathological features of patients with PC. Then a novel anti-Trop2 Fab antibody was conjugated with Doxorubicin (DOX) to form Trop2Fab-DOX, an antibody-drug conjugate. This Trop2Fab-DOX conjugate was characterized by cell ELISA and immunofluorescence assay. MTT and wound healing analyses were used to evaluate the inhibitory effect of Trop2Fab-DOX on PC cell growth in vitro, while xenograft nude mice model was established to examine the tumor-inhibitory effects of PC in vivo. High Trop2 expression was observed in PC tissues and Trop2 expression was associated with several malignant attributes of PC patients, including overall survival. Trop2Fab-DOX can bind to the Trop2-expressing PC cells and provide an improved releasing type of DOX. In addition, Trop2Fab-DOX inhibited the proliferation and suppressed the migration of PC cells in a dose-dependent manner in vitro, while inhibited the growth of PC xenografts in vivo. Trop2 is a specific marker for PC, and a novel Trop2Fab-DOX ADC has a potent antitumor activity

\section{INTRODUCTION}

Pancreatic carcinoma (PC) is one of the most aggressive forms of digestive tract malignancies, and it ranks eighth in cancer-related mortality worldwide $[1,2]$. The prognosis of patients with PC is extremely poor, with a 5 -year survival rate of $1-4 \%$, typically because of high lethality, delayed diagnosis, early metastasis, and severe progression $[3,4]$. So far, conventional PC treatment merely relies on chemotherapy and radiotherapy. Although some novel approaches have been introduced for PC treatment in latest years, none can effectively improve its overall survival $[5,6]$. It is thereby of timely importance to develop a novel treatment strategy that can predict the prognosis and improve therapeutic outcome in patients with PC.

Human trophoblastic cell surface antigen 2 (Trop2), also known as TACSTD2, EGP-1 or GA733-1, is a 
cell-surface glycoprotein, and belongs to the TACSTD gene family [7-9]. Trop2 expression was detected in a variety of human cancer cells, and its elevated expression is often associated with poor prognoses of breast, colon, and gastric cancers [10-12]. Moreover, the distribution of Trop2 is more differentiated in human cancers, suggestive of a certain oncogenic characteristic of Trop2 as a promising novel target for personalized treatment $[13,14]$.

Trop2 antibody has been constructed and tested by our former research, and human anti-Trop2 engineering antibody was used in immunohistochemistry (IHC) analysis [15] to investigate the inhibitory effectiveness of anti-Trop2 Fab antibody (Trop2Fab) in breast cancer [16]. For practical use, it is of added interest to motivate the application of Trop2Fab in cancer therapy with a more extended scale or circumstance, such as developing an antibody that can block the Trop2/MAPK pathway or conjugating an antibody with immunotoxins, radioimmunoconjugates or chemotherapy drugs [17].

Doxorubicin (DOX) is one of the most common chemotherapy drugs, and has been widely administrated in the clinical treatment for PC. Although patients under DOX therapy often experience serious side effects, such as heart failure, kidney toxicity and myelosuppression [18], DOX has some advantages for the research of antibody-drug conjugates, including high solubility, simple detectability and easy observability [19]. Recently, a number of drug molecules and delivery systems for DOX application have been developed with a promising prospect [20-22]. Based on the above, we hypothesized that a conjugate of Trop2Fab with DOX (Trop2Fab-DOX) could not only benefit from the high specificity of Trop2Fab fragment and but also reduce the possibility of side effects from DOX, as doing so can help characterize and optimize the clinical application of Trop2Fab.

To fill this void in knowledge, we first examined Trop2 expression in PC tissues and evaluated its relationship with the clinicopathological attributes of patients with PC. We next conjugated Trop2Fab with DOX to form an antibody-drug (Trop2Fab-DOX) conjugate. Further, we explored the antitumor effect of this Trop2FabDOX conjugate in vitro and in vivo.

\section{RESULTS}

\section{Detection of Trop2 expression by qPCR and IHC analyses}

For qPCR analysis, the expression of Trop2 mRNA was significantly higher in PC tissues than in the corresponding non-cancerous tissues when normalized to GAPDH ( $(4.6 \pm 0.38$ vs. $3.2 \pm 0.31, p=0.009)$ (Figure 1A). For IHC analysis, high Trop2 expression in cytoplasm and stroma was respectively detected in 114 of $189(60.3 \%)$ and 71 of 155 (45.8\%) PC tissues. In comparison, high Trop2 expression in cytoplasm and stroma was only witnessed in 6 of $87(6.90 \%)$ and 3 of 87 (3.44\%) noncancerous tissues. The differences of Trop 2 expression (in both cytoplasm and stroma) between PC tissues and non-cancerous tissues were statistically significant (both $p<0.05$ ).

The typical IHC staining for Trop2 expression and its relationship with important clinical characteristics in patients with PC are presented in Figure 1B and Table 1, respectively. High Trop2 expression in cytoplasm was significantly correlated with tumor location $(p=0.046)$, lymph nodes metastasis $(p=0.027)$, and TNM stage $(p=0.031)$, while high Trop2 expression in stroma was remarkably associated with perineural invasion $(p=0.024)$, vascular invasion $(p=0.047)$, lymph nodes metastasis $(p=0.020)$ and TNM stage $(p=0.003)$.

\section{Survival analysis}

Both univariate and multivariate analyses consistently revealed that cytoplasm expression of Trop2 was the most significant predictor for poor survival in 189 patients with PC ( $p=0.002$ and 0.013 , respectively) (Table 2). The Kaplan-Meier survival curves also demonstrated that $\mathrm{PC}$ patients with high Trop2 expression suffered a significantly shorter survival time (Figure 1C).

\section{Characterization of Trop2Fab}

The Trop2Fab was previously constructed in our laboratory [16] and was further characterized in this present study. In FACS analysis, the population of Trop2Fabtreated BxPc3 and PL45 cells was clearly separated from untreated cells by fluorescent intensity, with no observable difference between Trop2Fab-treated and untreated NIH3T3 cells (Figure 2A). In immunofluorescence assay, Trop2Fab was found to combine with BxPc3 and PL45 cells, and positive green signals were mainly detected around cell surface. In contrast, NIH3T3 cells exhibited negative signals (Figure 2B).

\section{Characterization of Trop2Fab-DOX}

After the conjugation of Trop2Fab with DOX, the DOX release profiles were detected. As is shown in Figure $4 \mathrm{~A}$ and $4 \mathrm{~B}$, the DOX release behavior from Trop2FabDOX was stable in $\mathrm{pH} 7.2 \mathrm{PBS}$, and the amount of cumulated DOX release reached nearly $15.0 \%$ over 7 days (Figure 3A). In comparison, the DOX was easier to release in $\mathrm{pH} 4.0$ PBS than that in $\mathrm{pH} 7.2 \mathrm{PBS}$, and almost $90.0 \%$ DOX was released within 5 days (Figure 3B). It is mainly due to that the amide bond of Trop2Fab-DOX is solid in neutral solutions while vulnerable in acidic solutions. Moreover, as shown in cell ELISA analysis (Figure 3C), both Trop2Fab-DOX and Trop2Fab could specifically bind to BxPc3 and PL45 cells in a dose-dependent manner, 
Table 1: Association of Trop2 expression with clinical attributes of PC

\begin{tabular}{|c|c|c|c|c|c|c|c|c|c|c|}
\hline \multirow[b]{2}{*}{ Groups } & \multirow[b]{2}{*}{ No. } & \multicolumn{4}{|c|}{ Trop2 expression in cytoplasm } & \multirow[b]{2}{*}{ No. } & \multicolumn{4}{|c|}{ Trop2 expression in stroma } \\
\hline & & $\begin{array}{c}\text { Low or no } \\
\text { expression } \\
(\%)\end{array}$ & $\begin{array}{c}\text { High } \\
\text { expression } \\
(\%)\end{array}$ & $\begin{array}{c}\text { Pearson } \\
\chi^{2}\end{array}$ & $\begin{array}{c}p \\
\text { value }\end{array}$ & & $\begin{array}{r}\text { Low or no } \\
\text { expression } \\
(\%)\end{array}$ & $\begin{array}{c}\text { High } \\
\text { expression } \\
(\%)\end{array}$ & $\begin{array}{c}\text { Pearson } \\
\chi^{2}\end{array}$ & $\underset{\text { value }}{p}$ \\
\hline \multicolumn{11}{|l|}{ Age (years) } \\
\hline$\leq 60$ & 65 & $26(40.00)$ & $39(60.00)$ & 0.757 & 0.384 & 57 & $33(57.89)$ & $24(42.11)$ & 0.614 & 0.433 \\
\hline$>60$ & 99 & $33(33.33)$ & $66(66.67)$ & & & 84 & $43(51.19)$ & $41(48.81)$ & & \\
\hline Insufficient data & 25 & 16 & 9 & & & 14 & 8 & 6 & & \\
\hline \multicolumn{11}{|l|}{ Gender } \\
\hline Male & 102 & $35(34.31)$ & $67(65.69)$ & 1.450 & 0.228 & 87 & $49(56.32)$ & $38(43.68)$ & 0.082 & 0.775 \\
\hline Female & 74 & $32(43.24)$ & $42(56.76)$ & & & 63 & $34(53.97)$ & $29(46.03)$ & & \\
\hline Insufficient data & 13 & 8 & 5 & & & 5 & 1 & 4 & & \\
\hline \multicolumn{11}{|l|}{ Tumor size $(\mathrm{cm})$} \\
\hline$\leq 2$ & 15 & $6(40.00)$ & $9(60.00)$ & 0.139 & 0.933 & 14 & $10(71.43)$ & $4(28.57)$ & 1.404 & 0.496 \\
\hline $2-3$ & 35 & $14(40.00)$ & $21(60.00)$ & & & 28 & $15(53.57)$ & $13(46.43)$ & & \\
\hline$>3$ & 95 & $35(36.84)$ & $60(63.16)$ & & & 83 & $46(55.42)$ & $37(44.58)$ & & \\
\hline Insufficient data & 44 & 20 & 24 & & & 30 & 13 & 17 & & \\
\hline \multicolumn{11}{|l|}{ Tumor location } \\
\hline Head & 97 & $33(34.02)$ & $64(65.98)$ & 6.151 & $0.046^{*}$ & 79 & $37(46.84)$ & $42(53.16)$ & 4.549 & 1.103 \\
\hline Body + Tail & 49 & $18(36.73)$ & $31(63.27)$ & & & 45 & $30(66.67)$ & $15(33.33)$ & & \\
\hline Insufficient data & 43 & $24(55.81)$ & $19(44.19)$ & & & 31 & $17(54.84)$ & $14(45.16)$ & & \\
\hline \multicolumn{11}{|l|}{ Differentiation } \\
\hline Well + Moderate & 149 & $58(38.93)$ & $91(61.07)$ & 0.168 & 0.682 & 123 & $65(52.85)$ & $58(47.15)$ & 0.436 & 0.509 \\
\hline Poor & 40 & $17(42.50)$ & $23(57.50)$ & & & 32 & $19(59.38)$ & $13(40.63)$ & & \\
\hline \multicolumn{11}{|l|}{ Perineural invasion } \\
\hline Positive & 64 & $23(35.94)$ & $41(64.06)$ & 0.236 & 0.627 & 54 & $27(50.00)$ & $27(50.00)$ & 5.114 & $0.024 *$ \\
\hline Negative & 14 & $6(42.86)$ & $8(57.14)$ & & & 13 & $11(84.62)$ & $2(15.38)$ & & \\
\hline Insufficient data & 111 & 46 & 65 & & & 88 & 46 & 42 & & \\
\hline \multicolumn{11}{|l|}{ Vascular invasion } \\
\hline Positive & 20 & $7(35.00)$ & $13(65.00)$ & 0.333 & 0.564 & 17 & $7(41.18)$ & $10(58.82)$ & 3.952 & $0.047 *$ \\
\hline Negative & 47 & $20(42.55)$ & $27(57.45)$ & & & 42 & $29(69.05)$ & $13(30.95)$ & & \\
\hline Insufficient data & 122 & 48 & 74 & & & 96 & 48 & 48 & & \\
\hline \multicolumn{11}{|c|}{ Lymph nodes metastasis } \\
\hline Positive & 40 & $10(25.00)$ & $30(75.00)$ & 4.908 & $0.027 *$ & 34 & $13(38.24)$ & $21(61.76)$ & 5.433 & $0.020^{*}$ \\
\hline Negative & 90 & $41(45.56)$ & $49(54.44)$ & & & 79 & $49(62.03)$ & $30(37.97)$ & & \\
\hline Insufficient data & 59 & 24 & 35 & & & 42 & 22 & 20 & & \\
\hline \multicolumn{11}{|l|}{ TNM stage } \\
\hline Stage I & 58 & $25(43.10)$ & $33(56.90)$ & 6.950 & $0.031 *$ & 56 & $40(71.43)$ & $16(28.57)$ & 11.340 & $0.003 *$ \\
\hline Stage II & 31 & $12(38.71)$ & $19(61.29)$ & & & 26 & $14(53.85)$ & $12(46.15)$ & & \\
\hline Stage III-IV & 54 & $11(20.37)$ & $43(79.63)$ & & & 49 & $19(38.78)$ & $30(61.22)$ & & \\
\hline Insufficient data & 46 & 27 & 19 & & & 24 & 11 & 13 & & \\
\hline
\end{tabular}
$* p<0.05$.

while there was barely any binding to NIH3T3 cells. Absorbance values of Trop2Fab-DOX and Trop2Fab in Trop2-positive and -negative cells differed significantly. In immunofluorescence assay, Trop2Fab-DOX could specifically bind to Trop2-positive BxPc3 and PL45 cells. The cells treated with Trop2Fab-DOX exhibited green fluorescence around cell surface, while no signal was detected in NIH3T3 cells incubated with Trop2Fab-DOX (Figure 3D).

\section{Route of Trop2Fab-DOX transported within PC cells}

To explore the process of DOX transportation by Trop2Fab and further compare the internalized capability of Trop2Fab-DOX and DOX, BxPc3 and NIH3T3 cells were incubated with Trop2Fab-DOX and DOX at different time points. With the prolongation of culture time, a growing amount of red fluorescence was observed 
Table 2: Univariate and multivariate analysis of prognostic factors in $\mathrm{PC}$ for overall survival

\begin{tabular}{|c|c|c|c|c|c|c|}
\hline \multirow{2}{*}{ Variable } & \multicolumn{3}{|c|}{ Univariate analysis } & \multicolumn{3}{|c|}{ Multivariate analysis } \\
\hline & HR & $p$ value & $95 \% \mathrm{CI}$ & HR & $p$ value & $95 \% \mathrm{CI}$ \\
\hline $\begin{array}{l}\text { Trop2 expression in cytoplasm } \\
\text { High versus Low or no }\end{array}$ & 3.592 & $0.002 *$ & $1.605-8.036$ & 3.337 & $0.013 *$ & $1.294-3.077$ \\
\hline $\begin{array}{l}\text { Trop2 expression in stroma } \\
\text { High versus Low or }\end{array}$ & 2.100 & $0.043^{*}$ & $1.024-4.306$ & 1.401 & 0.401 & $0.638-3.077$ \\
\hline $\begin{array}{l}\text { Gender } \\
\quad \text { Female versus Male }\end{array}$ & 1.392 & 0.368 & $0.677-2.863$ & & & \\
\hline $\begin{array}{l}\text { Age (years) } \\
\leq 60 \text { versus }>60\end{array}$ & 0.893 & 0.744 & $0.452-1.762$ & & & \\
\hline $\begin{array}{l}\text { Tumor size }(\mathrm{cm}) \\
\leq 2 \text { versus } 2-3 \text { versus }>3\end{array}$ & 0.774 & 0.298 & $0.477-1.254$ & & & \\
\hline $\begin{array}{l}\text { Tumor location } \\
\text { Head versus Body }+ \text { Tail }\end{array}$ & 0.666 & 0.095 & $0.414-1.072$ & & & \\
\hline \multicolumn{7}{|l|}{ Differentiation } \\
\hline Well + Moderate versus versus Poor & 1.746 & 0.160 & $0.803-3.797$ & & & \\
\hline \multicolumn{7}{|l|}{ Perineural invasion } \\
\hline Positive versus Negative & 0.575 & 0.593 & $0.076-4.365$ & & & \\
\hline \multicolumn{7}{|l|}{ Vascular invasion } \\
\hline Positive versus Negative & 1.461 & 0.419 & $0.582-3.669$ & & & \\
\hline \multicolumn{7}{|l|}{ Lymph nodes metastasis } \\
\hline Positive versus Negative & 2.133 & $0.038 *$ & $1.041-4.370$ & 1.780 & 0.146 & $0.818-3.873$ \\
\hline $\begin{array}{l}\text { TNM stage } \\
\text { Stage I versus Stage II versus Stage III-IV }\end{array}$ & 1.295 & 0.235 & $0.846-1.982$ & & & \\
\hline
\end{tabular}

$* p<0.05$.

in the membrane, cytoplasm and nuclei of BxPc3 cells treated with Trop2Fab-DOX, while the red fluorescence remained stable in the nuclei of BxPc3 cells treated with DOX. In contrast, NIH3T3 cells only exhibited red fluorescence in the nuclei when treated with DOX, while no staining was observed when treated with Trop2FabDOX (Figure 4).

\section{Trop2Fab-DOX inhibits tumor growth in vitro}

MTT assay and wound healing assay were performed to evaluate the inhibitory effect of Trop2FabDOX in Trop2-expressing PC cells. There were significant differences in inhibitory rate and migration rate of $\mathrm{PC}$ cells between Trop2Fab-DOX group and Trop2Fab group $(p<0.05)$ or PBS group $(p<0.05)$. For MTT assay, at $10 \mu \mathrm{g} / \mathrm{mL}$ of Trop2Fab-DOX after $72 \mathrm{~h}$ incubation, the growth of BxPc3 cells and PL45 cells were inhibited by $87.63 \%$ and $73.78 \%$, respectively. Trop 2 Fab-DOX showed a potent and dose-dependent inhibitory effect on both PC cells and it also demonstrated more powerful tumor-inhibitory ability than DOX in BxPc3 cells. In contrast, Trop2Fab-DOX, Trop2Fab, unrelated Fab, and PBS exhibited modest or no inhibitory effects on NIH3T3 cells, although DOX still exerted an inhibitory ability (Figure 5A, 5B and 5C). For wound healing assay, the migration rate of $\mathrm{BxPc} 3$ cells and PL45 cells were decreased to $28.62 \%$ and $34.75 \%$ after incubation with $10 \mu \mathrm{g} / \mathrm{mL}$ of Trop2Fab-DOX for $72 \mathrm{~h}$. Trop2Fab-DOX also demonstrated a dose-dependent inhibitory effect on cell migration. For NIH3T3 cells, the wound closure rates in Trop2Fab-DOX, Trop2Fab, unrelated Fab, and PBS showed no significant difference (Figure 5D, 5E and 5F). We also compared the $\mathrm{IC}_{50}$ of Trop2Fab-DOX and DOX indifferent PC cell lines. The fluorescence intensity of Trop2 was detected by FACS analysis to represent Trop2 expression levels of PC cells. As is shown in Table 3, according the concentration of effective-DOX, the ratio of $\mathrm{IC}_{50}$ (Trop2Fab-DOX) to $\mathrm{IC}_{50}(\mathrm{DOX})$ was 4.92 in BxPc3 cells with high Trop2 expression (98.12\%) while about 4.43 in PL45 cells with moderate Trop2 expression $(73.65 \%)$. For NIH3T3 cells, the ratio of $\mathrm{IC}_{50}$ can not be calculated because Trop2Fab-DOX barely showed inhibitory effects. The results indicated that the inhibitory effects of Trop2Fab-DOX are immunological specific in PC cells which have high Trop2 expression. 
Table 3: The $\mathrm{IC}_{50}$ of DOX in PC cells treated with DOX or Trop2Fab-DOX with equivalent effectiveconcentration of $\mathrm{DOX}$

\begin{tabular}{|c|c|c|c|c|c|c|}
\hline \multirow{2}{*}{ Cell lines } & \multicolumn{2}{|c|}{$\operatorname{DOX}(\mu \mathrm{g} / \mathrm{mL})$} & \multicolumn{2}{|c|}{ Trop2Fab-DOX $(\mu \mathrm{g} / \mathrm{mL})$} & \multirow{2}{*}{ Ratio of $\mathrm{IC}_{50}$} & \multirow{2}{*}{$\begin{array}{c}\text { Trop2 } \\
\text { expression }\end{array}$} \\
\hline & $\mathrm{IC}_{50}$ & $95 \% \mathrm{CI}$ & $\mathrm{IC}_{50}$ & $95 \%$ CI & & \\
\hline BxPc3 & 0.86 & $0.376-0.993$ & 4.23 & $2.659-7.575$ & 4.92 & 98.12 \\
\hline PL45 & 0.35 & $0.168-0.697$ & 1.55 & $0.437-4.669$ & 4.43 & 73.65 \\
\hline NIH3T3 & 0.41 & $0.275-0.743$ & - & & & \\
\hline
\end{tabular}

*The Trop2 expression was illustrated as the value of fluorescence intensity by FACS. $\mathrm{IC}_{50}(\mathrm{DOX})$. The $\mathrm{IC}_{50}$ value of DOX

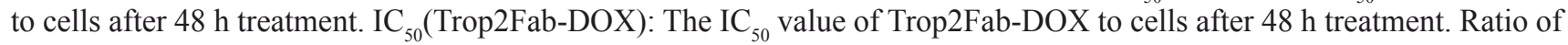
$\mathrm{IC}_{50}: \mathrm{IC}_{50}\left(\right.$ Trop2Fab-DOX)/IC $\mathrm{I}_{50}(\mathrm{DOX})$.

\section{Trop2Fab-DOX inhibits tumor growth in vivo}

BxPC3 xenograft nude mice model was confirmed by IHC analysis for Trop2 expression (Figure 6A) and this model was employed to evaluate the tumor inhibitory effect of Trop2Fab-DOX in vivo. At 30th day, mean body weight of nude mice showed no substantial differences between all treated groups (data not shown). Three mice died (at 16th, 19th and 27th days) in high concentration DOX group, and two mice died (at 16th and 21st days) in low concentration DOX group. In contrast, no animal death was observed in other treated groups. As shown in Figure $6 \mathrm{~B}$ and $6 \mathrm{C}$, at 30th day the tumor volume and weight of PBS control group was 1123.8 (s.d.: 106.93) $\mathrm{mm}^{3}$ and 899.0 (s.d.: 30.43 ) mg, respectively. In contrast, the tumor size and weight were decreased to 428.8 (s.d.: 36.77 ) $\mathrm{mm}^{3}$ and 343.0 (s.d.: 36.57 ) $\mathrm{mg}$ in low concentration of DOX treated group, to 408.1 (s.d.: 29.41) $\mathrm{mm}^{3}$ and 326.5 (s.d.: 70.33) $\mathrm{mg}$ in high concentration of DOX treated group, to 346.6 (s.d.: 40.12 ) $\mathrm{mm}^{3}$ and 277.2
A

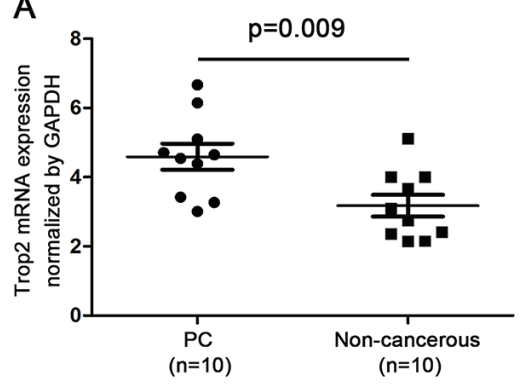

C

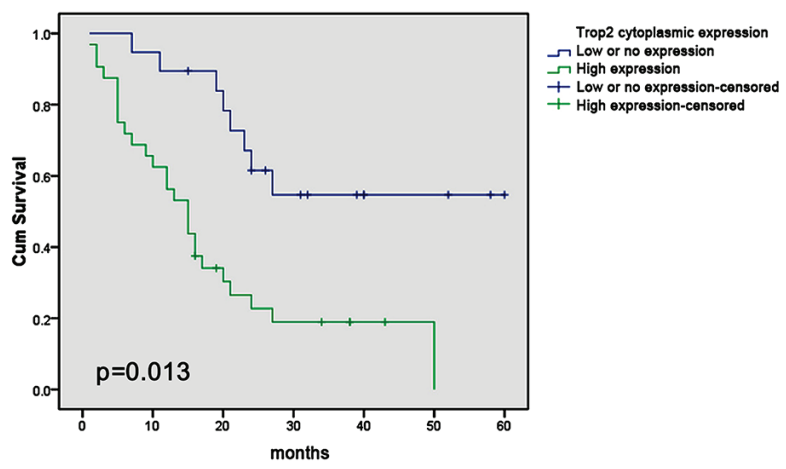

B

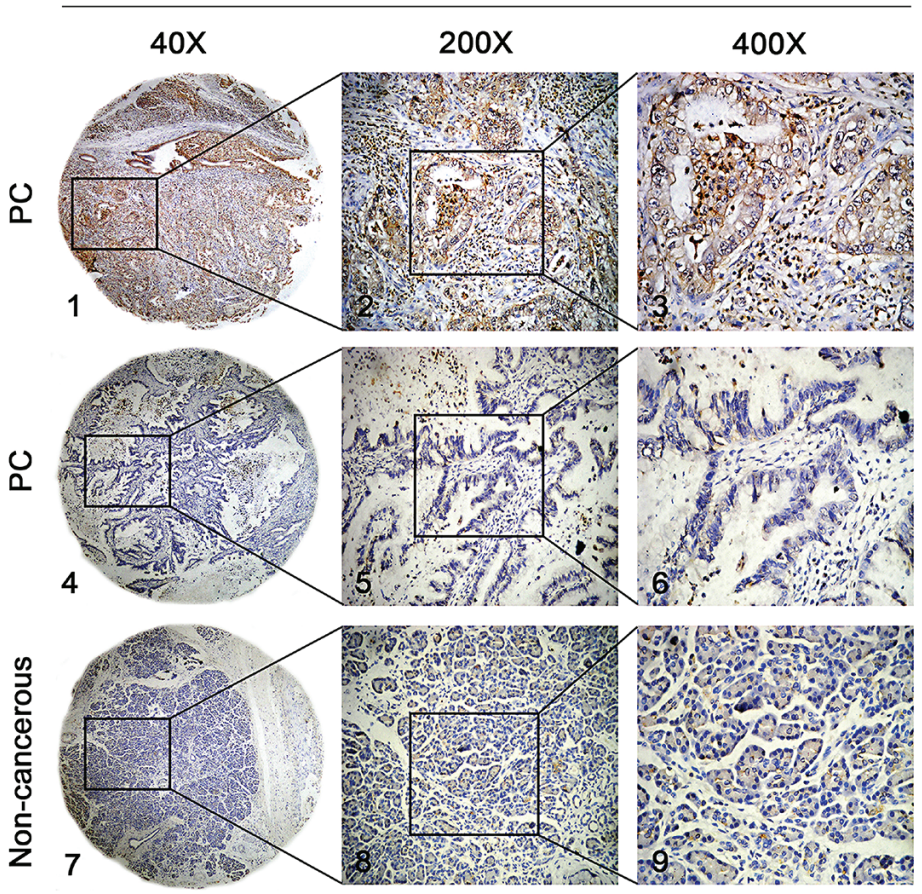

Figure 1: Trop2 expression in PC tissues and its relationship with survival status in patients with PC. (A) Trop2 expression in pancreatic carcinoma (PC) tissues and non-cancerous tissues. One-step quantitative real-time polymerase chain reaction (qPCR) indicated that Trop2mRNA expression in PC tissues (4.6 \pm 0.38$)$ was significantly higher than that in non-cancerous tissues $(3.2 \pm 0.31)\left({ }^{*} p=0.009\right)$. (B) Representative images of Trop2 protein expression in PC and the corresponding non-cancerous tissues with tissue microarray (TMA) by immunohistochemistry (IHC) analysis. B1, B2 and B3 High staining of Trop2 in PC samples. B4, B5 and B6 Low staining of Trop2 in PC samples. B7, B8 and B9 Low staining of Trop2 in non-cancerous samples. Original magnification $\times 40$ in B1, B4 and B7; $\times 200$ in B2, B5 and B8; $\times 400$ in B3, B6 and B9. (C) Kaplan-Meier curve demonstrated that overall survival rate in PC patients with high Trop2 expression (green line) was significantly lower than that in patients with low or no Trop2 expression (blue line). 
(s.d.: 60.69) $\mathrm{mg}$ in Trop2Fab-DOX treated group, and to 880.2 (s.d.: 90.44) $\mathrm{mm}^{3}$ and 704.2 (s.d.: 68.92) $\mathrm{mg}$ in Trop2Fab treated group, respectively. The inhibition rate of tumor growth in each treatment group is summarized in Figure 6D, and Trop2Fab-DOX was found to exert the most significant inhibitory effect on xenograft PC tumor growth.

\section{DISCUSSION}

Although various therapeutic mono-clonal antibodies (mAbs) have been successfully applied in clinical practice, free antibodies targeting cell surface antigens that are expressed on tumors become less therapeutically effective by themselves or even though in combination with chemotherapeutic drugs [23, 24]. A wealth of evidence supports the claim that ADCs can enhance antitumor activity, reduce systemic toxicity and bring clinical benefits $[25,26]$. The key factors for ADC development mainly include the selection of specific antigen, optimization of the kinetics, and efficacy of ADCs [27].

Trop2 has been identified as an oncogene for several human cancers [28-30] and a number of strategies targeting Trop2 have gained promising achievements $[13,31,32]$. What Trop2 functions in PC and whether the application of Trop2Fab in PC treatment is beneficial deserves further exploration.

We first observed a significantly higher level of Trop2 expression in PC tissues than in non-cancerous tissues by qPCR test and IHC analysis. Also Trop2 expression was identified to be closely correlated with certain malignant behaviors of PC patients. Further survival analysis demonstrated that the prognosis of PC

A
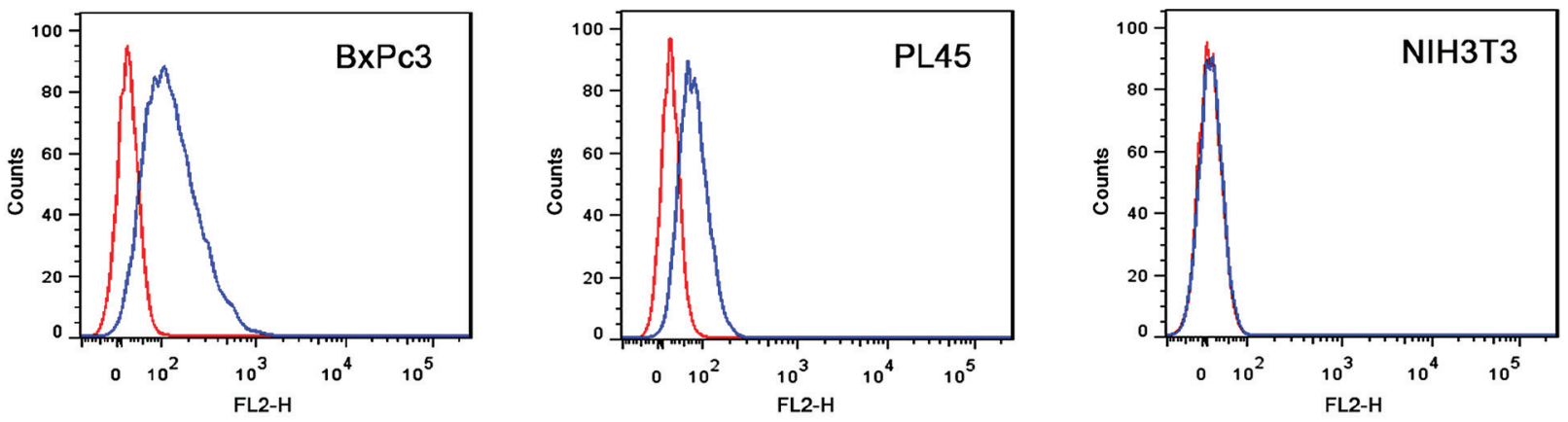

B
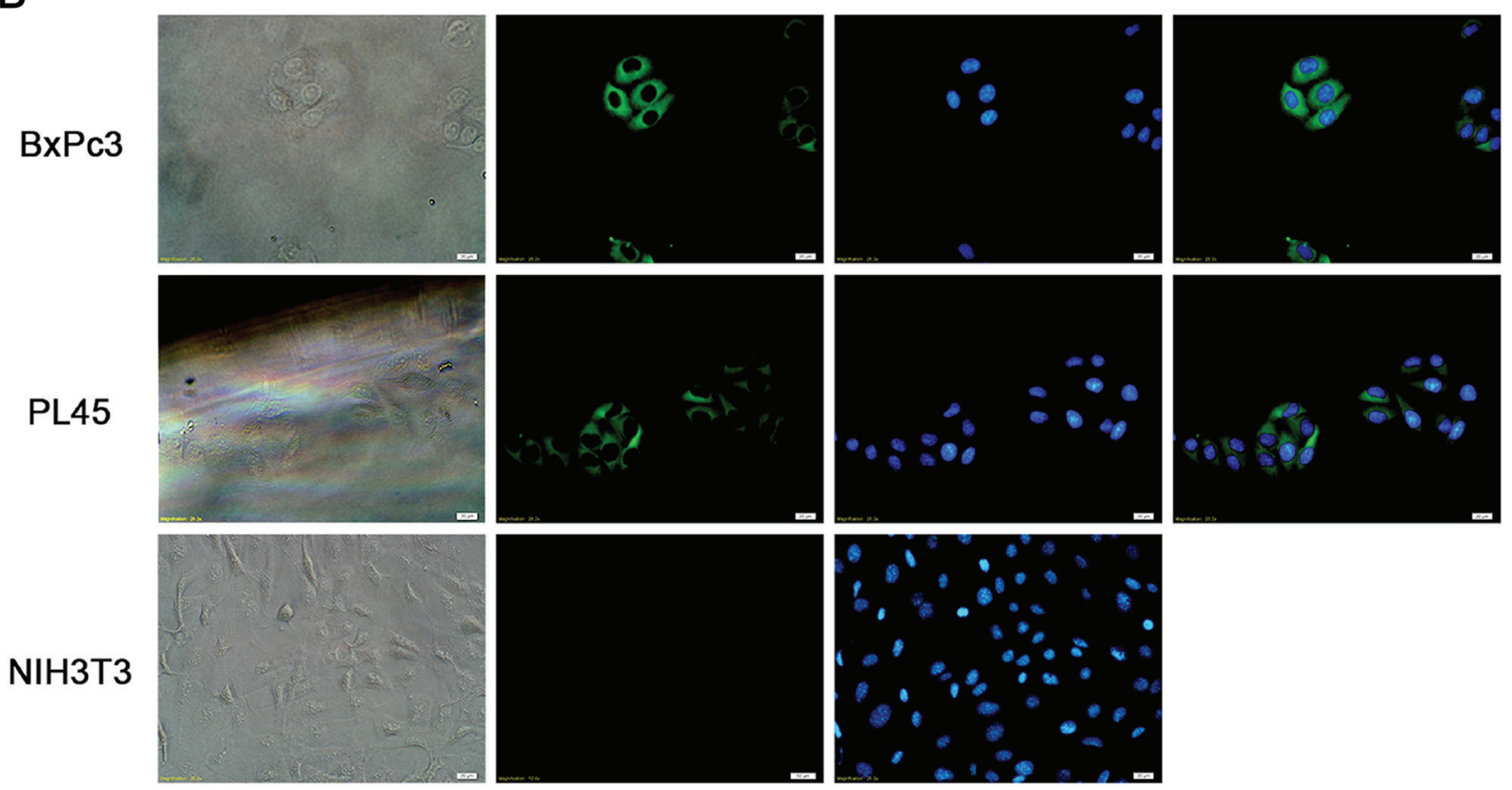

Figure 2: Trop2Fab reacts with Trop2-expressing PC cells. (A) FACS analysis of BxPC3, PL45, and NIH3T3 cell lines. The fluorescent intensity differed significantly between Trop2-positive cells (BxPC3 and PL45) and Trop2-negative cells (NIH3T3). (B) Immunofluorescence assay showed that Trop2Fab could combine with BxPc3 and PL45 cells, and positive green signals were mainly located on cell surface, while NIH3T3 cells showed negative immunofluorescence signals. Blue signals were DAPI staining for cell nuclei. 
patients with high Trop2 expression was critically worse than that of patients with low or no expression. Collective data on basis of previous research and the present study supported the notion of Trop2 as a appealing therapeutic target against cancer [13, 14, 28-30].

We previously stated that only high concentration of Trop2Fab can exert a tumor inhibitory effect [16], which clearly restricted its application. It was noted that RS7 antibody could rapidly internalize into target cells but barely had therapeutic activity in unconjugated form [33-35]. Echoing from this inspiration, we followed the rationale of $\mathrm{ADCs}$ and successfully constructed a conjugate of Trop2Fab-DOX, which can presumably improve the anti-tumor activity of Trop $2 \mathrm{Fab}$.

For ADCs, the linker is critical for maintaining the stability of the ADCs and releasing active drug in appropriate time and site [36, 37]. Trop2Fab-DOX is constructed by chemical synthesis, which contains an amide bond that is relatively stable in $\mathrm{pH}$ 7.2 PBS, while is able to release drug at $\mathrm{pH} 4.2$. The data of DoX release test implies that this Trop2Fab-DOX does not release drug in human plasma under neutral $\mathrm{pH}$ environment, but allows DOX to be released from the antibody vector after $\mathrm{pH}$ change. Moreover, as evaluated by cell ELISA and immunofluorescence assay, the Trop2Fab-DOX conjugate could maintain the ability of recognizing Trop2 protein in cell membrane. Moreover, this conjugate had a particular way of releasing DOX. The observation of the process of drug transport in $\mathrm{BxPc} 3$ cells rendered us to quickly detect positive signals in nuclei only after cells incubated with DOX, and the reason may be that free DOX was delivered into cells by a passive diffusion style and bound to cell nucleus rapidly and stably from the beginning, and such binding barely changed regardless of elongation of incubation time. While as time went on, metabolic fluorescence was distributed on the surface, cytoplasm and nuclei of BxPc3 cells treated with Trop2Fab-DOX, implying the equilibrious transportation of DOX in BxPc3 cells. Meanwhile, the active DOX released from the conjugate and partitioned to the nuclei of $\mathrm{BxPc} 3$ cells was lower than the free DOX. Contrastingly, there was no detectable fluorescence in NIH3T3 cells treated with Trop2Fab-DOX, while high fluorescence in nucleus was observed in NIH3T3 cells treated with free DOX. These
A

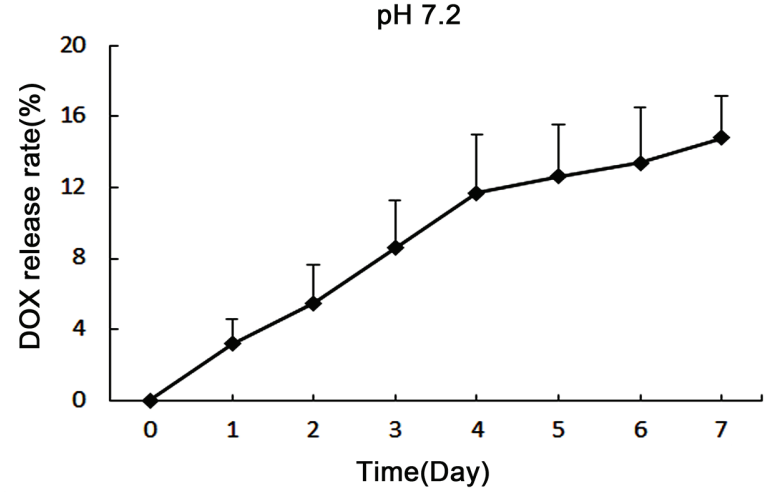

C

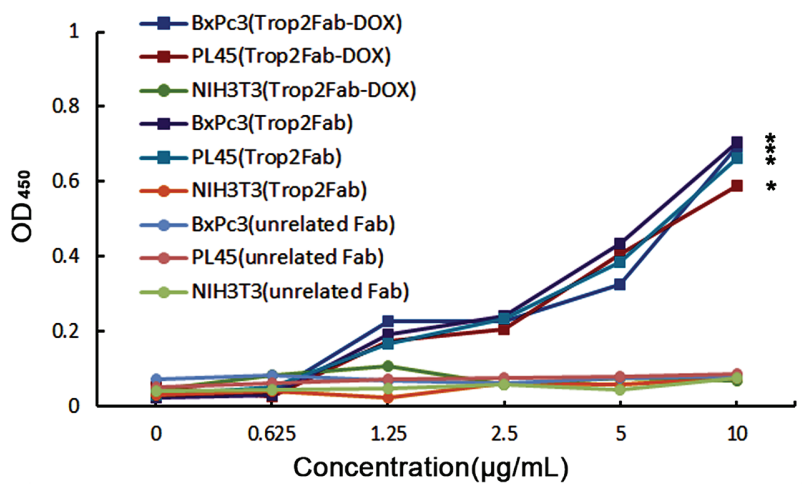

B

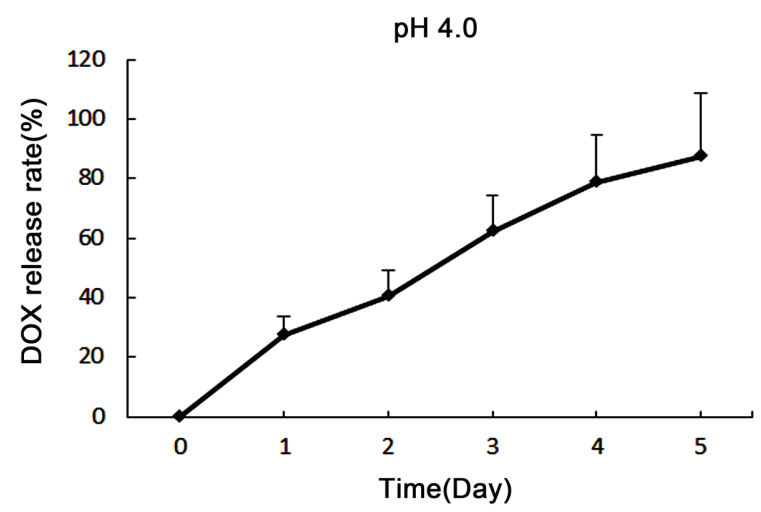

Figure 3: Characterization of Trop2Fab-DOX. (A) The Trop2Fab-DOX was stable in pH 7.2 PBS. The amount of cumulated DOX release was about $15.0 \%$ over 7 days. (B) The DOX released from Trop2Fab-DOX quickly in pH 4.0 PBS, and almost $90.0 \%$ DOX was released within 5 days. (C) BxPC3, PL45 and NIH3T3 were incubated with Trop2Fab-DOX and Trop2Fab $(0.625-10 \mu \mathrm{g} / \mathrm{mL})$. Both Trop2Fab-DOX and Trop2Fab can react with BxPC3 and PL45 cells specifically, but not with NIH3T3 cells. Absorbance values were analyzed by Variance Analysis. *Significant difference of absorbance values in BxPC3 and PL45 cells compared with NIH3T3 cells. $p<0.05$. (D) Binding efficacy of Trop2Fab-DOX was assessed by immunofluorescence observation. Both BxPC3 and PL45 cells presented green fluorescence after incubation with Trop2Fab-DOX. No signal was observed in NIH3T3 cells when incubated with Trop2Fab-DOX. Red signals were staining by commercial Trop2 antibody in PC cells and blue signals were DAPI staining for cell nuclei. 
findings collectively suggest that DOX was rarely released from Trop2Fab-DOX conjugate in non-Trop2 expressing cells, which further proved the high selectivity and great specificity of Trop2Fab-DOX.

Although an anti-Trop-2 IgG-SN-38 conjugate was verified by Cardillo et al to exert an antitumor effect [38], the use of the $\operatorname{IgG}$ antibody could not optimally recognize tumor marker since the existence of Fc fragments. In contrast, Fab antibody could reduce the false signals stemming from IgG antibody and improve the capability for identifying tumor antigen, such as Trop2 [39]. Moreover, Fab can facilitate trafficking of the antigens across cell membrane, rendering it more suitable to construct ADCs [40]. A recent study reported that a TriFab bispecific antibody TF12 was sufficiently retained on cancer cell surface, which made it suitable for pre-targeted imaging and therapy of Trop2 expressing cancers [41].

In following tumor-inhibitory experiments in vitro, our results of MTT assay and wound healing assay demonstrated that Trop2Fab-DOX can effectively inhibit

\section{Trop2Fab-DOX}
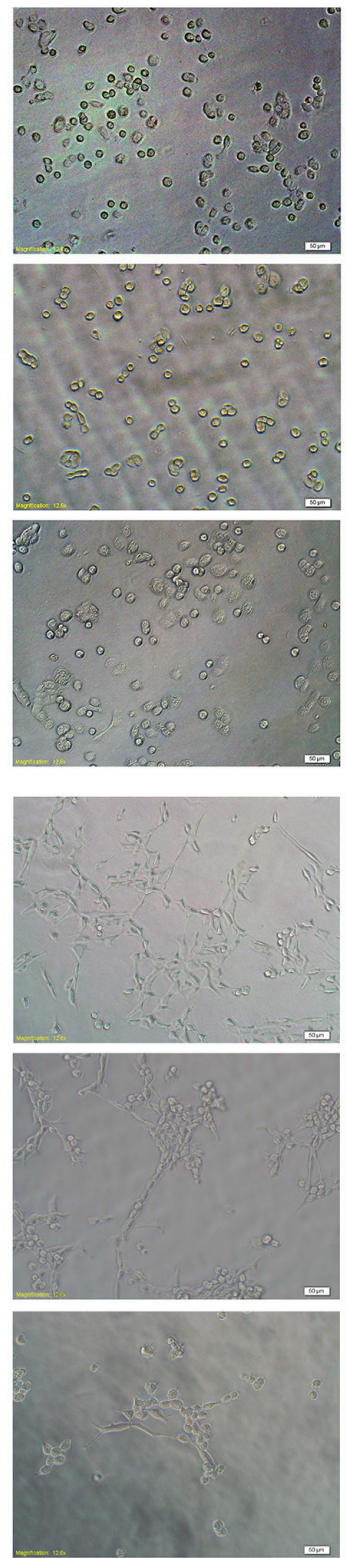
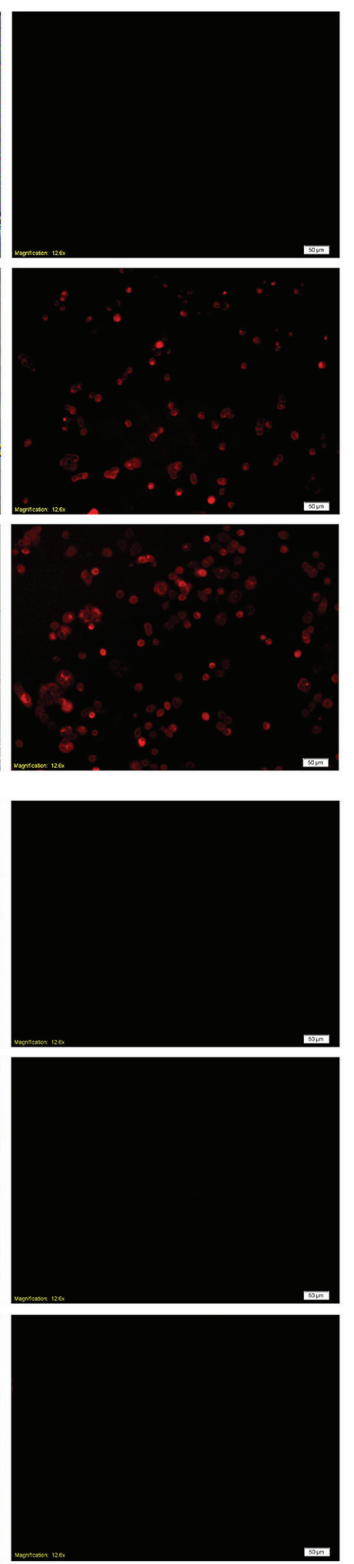

\section{DOX}
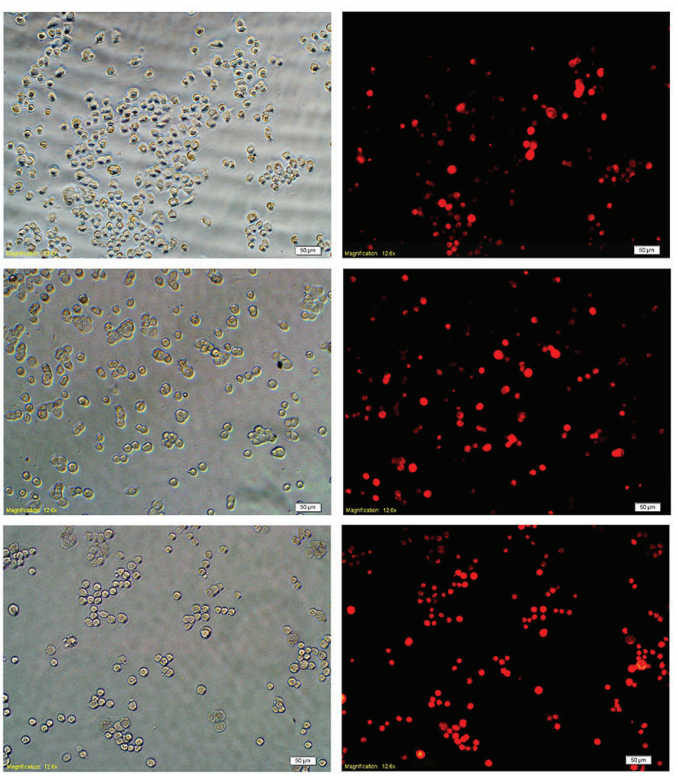

$1 \mathrm{~h}$

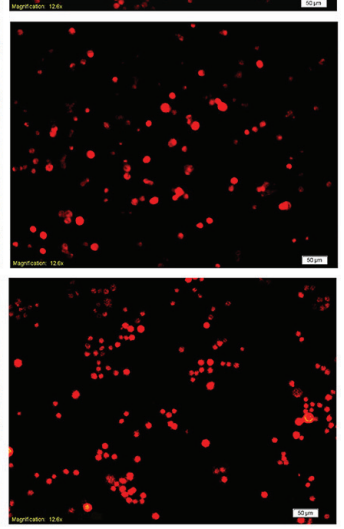

$2 \mathrm{~h}$
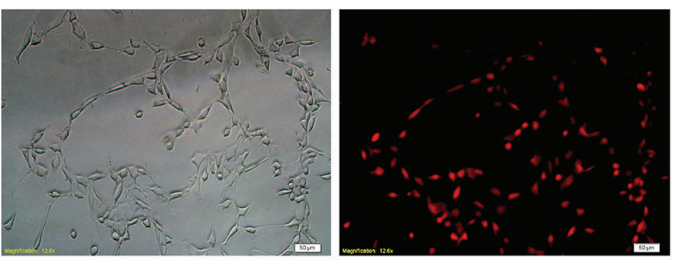

$1 \mathrm{~h}$
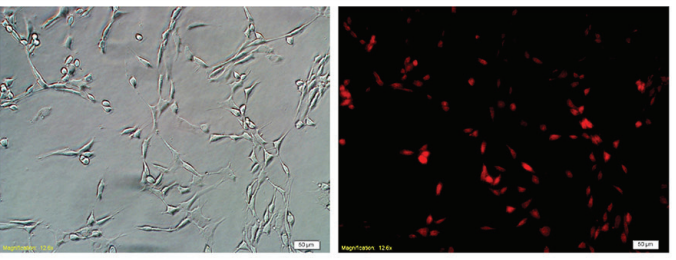

$2 \mathrm{~h}$
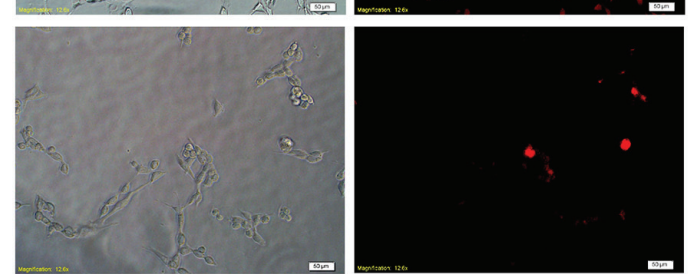

Figure 4: Detection of drug transport route by fluorescence microscopy. BxPC3 and NIH3T3 cells were incubated with Trop2Fab-DOX and free DOX for 1 h, 2 h, and 3 h, respectively. For BxPC3 cells, the Trop2Fab-DOX was gradually distributed, and with prolonged time, the signal of Trop2Fab-DOX can be observed in the membrane, cytoplasm, perinuclear area and nucleus. In contrast, red fluorescent signals were quickly detected in the nuclei of cells after incubation with free DOX and the signals barely changed with prolonged time. For NIH3T3 cells, no red fluorescent signal was observed when incubated with Trop2Fab-DOX. 

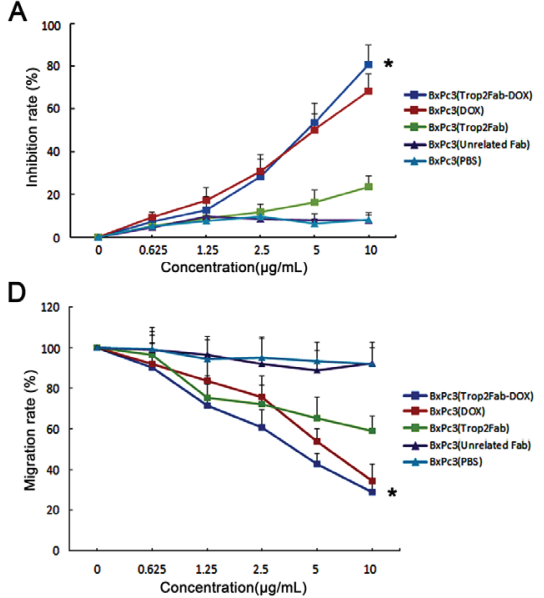

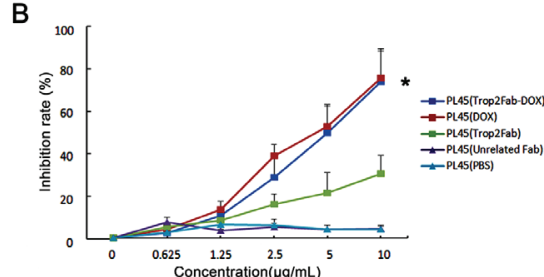

E

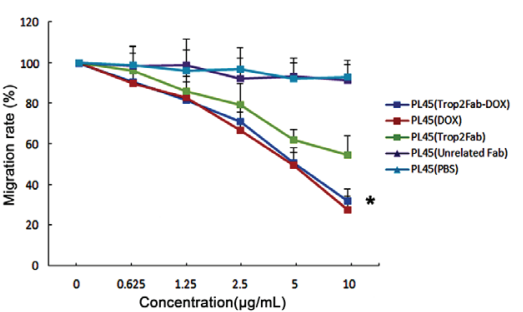

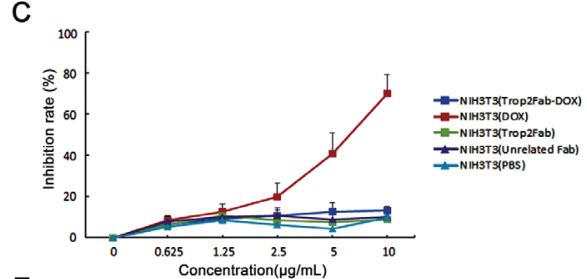

F

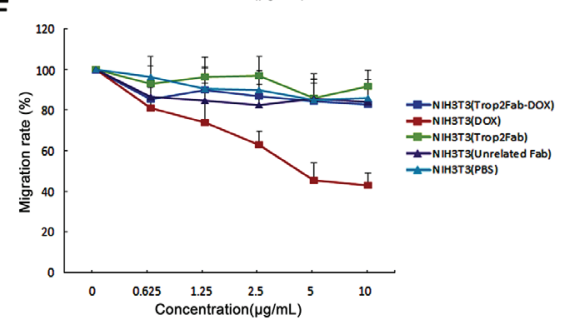

Figure 5: Trop2Fab-DOX inhibits the proliferation of PC cells in vitro. (A, B and C) MTT assay showed a dose-dependent inhibitory effect of Trop2Fab-DOX $(0.625-10 \mu \mathrm{g} / \mathrm{mL})$ on the proliferation of BxPC3 and PL45 cells, while this inhibitory effect on NIH3T3 cells was nonsignificant. *Significant difference in BxPC3 and PL45 cell lines with Trop2Fab-DOX (10 $\mu \mathrm{g} / \mathrm{mL})$ compared with PBS treatment. $p<0.05$. (D, E and F) Wound healing assay showed that the migration rate in BxPC3 and PL45 cells treated with Trop2FabDOX $(10 \mu \mathrm{g} / \mathrm{mL})$ was the lowest among all treated groups, the difference being statistically significant. While for NIH3T3 cells, wound closure rates in all treated groups showed no significant differences. *Significant difference in BxPC3 and PL45 cell lines with Trop2FabDOX $(10 \mu \mathrm{g} / \mathrm{mL})$ compared with PBS treatment. $p<0.05$.

A

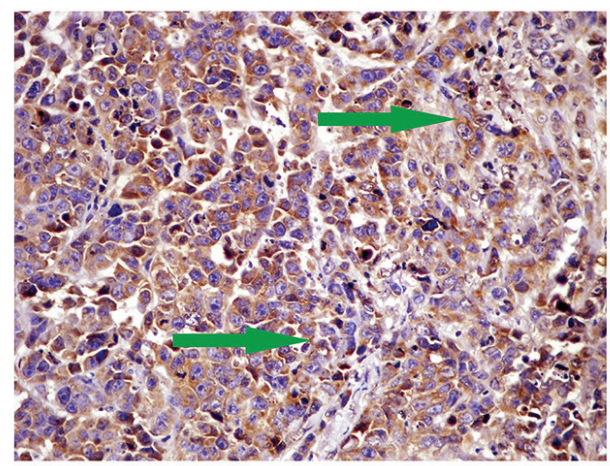

C

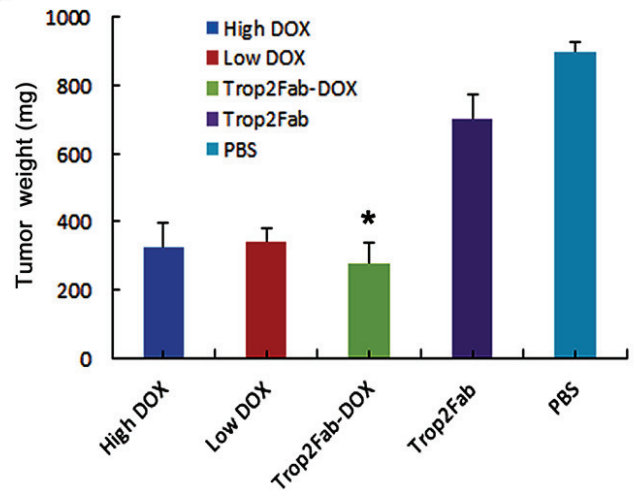

B

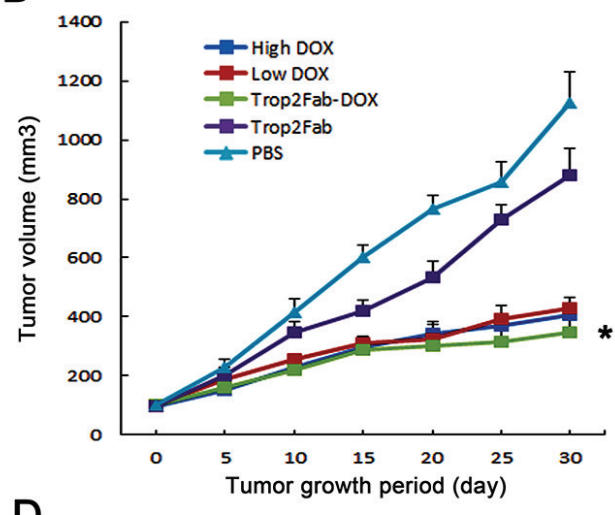

D

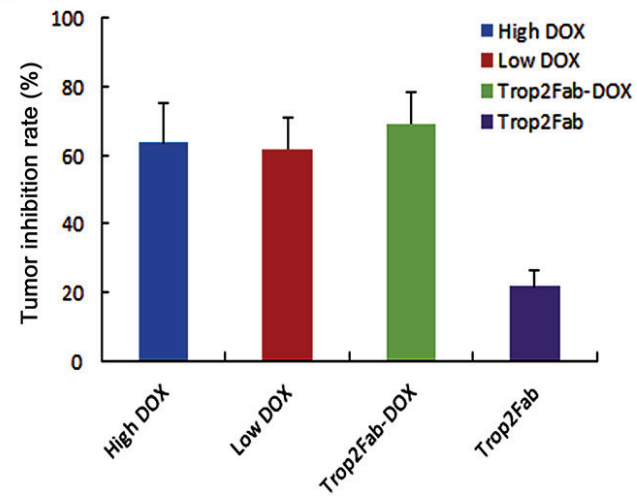

Figure 6: Trop2Fab-DOX inhibits the proliferation of PC cells in vivo. (A) positive Trop2 expression in xenograft mice was confirmed by IHC analysis. Green arrow showed the positive staining of Trop2 in the cytoplasm in xenograft tumors. (B) Comparison of tumor volume of xenograft tumors in different treated groups. ${ }^{*} p<0.05$ compared with control group. (C) Comparison of tumor weight of xenograft tumors in different treated groups. ${ }^{*} p<0.05$ compared with control group. (D) Comparison of tumor-inhibitory rates in different treated groups. The inhibition rates in high concentration of DOX, low concentration of DOX, Trop2Fab-DOX and Trop2Fab were 63.69\%, $61.84 \%, 69.16 \%$, and $21.67 \%$, respectively. 
proliferation and migration of PC cells. Also, we assessed the antitumor effect of Trop2Fab-DOX in vivo. Although DOX was potent to inhibit tumor growth, its efficacy was lower than that of Trop2Fab-DOX in BxPc3 cells, suggesting the superiority of Trop2Fab-mediated specific tumor targeting. In addition, Trop2Fab-DOX exerted the highest tumor inhibition rate in PC xenograft mice and no animal death occurred in Trop2Fab-DOX treatment group. In comparison, there were three deaths in DOX treatment group. On this basis, it is reasonable to speculate that the lethal toxicity of DOX was reduced due to ADC conjugation.

It is also worth mentioning that the diversity of Trop2 expression in human cancers. For example, Trop2 expression was exclusively localized to the membrane in ovarian cancer cells while stroma cells were regularly negative [30]. In comparison, Trop2 expression could be observed in both cancer cells and stroma cells in colorectal cancer [42]. As for PC, Fong et al. detected homogeneous membranous expression of Trop2 in cancer cells [43]. While in this present study, Trop2 expression was observed in both cytoplasm and stroma of PC cells. Hence despite the promising results presented here, it should be stressed that the different levels of Trop2 expressing in PC may result in differential biologic efficacies of Trop2Fab-DOX.

In summary, our findings herein provide convincing evidence that Trop2 is a specific marker for PC, and a novel Trop2Fab-DOX ADC has a potent antitumor activity. Moreover, this Trop2Fab-DOX is effective both in vitro and in vivo against $\mathrm{PC}$, and might serve as a promising target for cancer therapy that merits thorough preclinical researches in the future.

\section{MATERIALS AND METHODS}

\section{PC tissue samples}

Ten fresh PC tissues and the corresponding adjacent noncancerous tissues were obtained from the Department of Pathology, the Affiliated Cancer Hospital of Nanjing Medical University, Jiangsu Cancer Hospital. Simultaneously, 189 formalin-fixed, paraffin-embedded PC tissues and 87 non-cancerous tissues were obtained from patients undergoing surgical therapy for PC at the Affiliated Hospital of Nantong University between 2003 and 2010. Clinical data were collected from patient medical records. Tissue microarray (TMA) chips were generated using the manual Tissue Microarrayer System Quick Ray (UT06 UNITMA, Korea) in the Department of Pathology, the Affiliated Hospital of Nantong University. Survival time was calculated from the date of surgery to the date of death or last follow-up, whichever came first. Written informed consent was provided by all participants before participation in this study. All study protocols were reviewed and approved by the Human Research Ethics Committees of each local institution and all experimental methods were carried out in accordance with approved guidelines of Nantong University and Nanjing Medical University.

\section{Cell lines and reagents}

Two pancreatic adenocarcinoma cell lines (BxPC3 and PL45) and a mouse fibroblast cell line NIT3T3 were purchased from the Cell Bank of Chinese Academy of Sciences (Shanghai, China). BxPC3 and PL45 are two Trop2-positive cell lines [44] and NIH3T3 is a Trop2negative cell line. All cell lines were cultured in DMEM-H (Invitrogen, Carlsbad, CA, USA) supplemented with 10\% fetal bovine serum (FBS) (Gibco), penicillin (100 U/mL) and streptomycin $(100 \mathrm{lg} / \mathrm{mL})$. Human anti-Trop2 Fab antibody (Trop2Fab) and a self-made anti-rabies virus Fab antibody (unrelated Fab) were prepared in our laboratory. The commercial anti-Trop2 antibody for IHC analysis in TMA was purchased from the Abcam Co., Ltd (Abcam, England). Doxorubicin (DOX) $(2 \mathrm{mg} / \mathrm{mL})$ was kindly provided by the Southeast University.

\section{Detection of Trop2 expression by qPCR and IHC analyses}

For one-step quantitative real-time reverse transcription-polymerase chain reaction (qPCR) test, the primers for Trop2 were as follows: forward: 5'TAT TAC CTG GAC GAG ATT CCC C-3' and reverse: 5'-CCC CGA CTT TCT CCG GTT G-3'. Glyceraldehyde 3-phosphate dehydrogenase (GAPDH) was used as an internal control. The primers for GAPDH were as follows: forward: 5'-TGC ACC ACC AAC TGC TTA GC-3' and reverse: 5'-CTC ATG ACC ACA GTC CAT GCC-3'. Total RNA extraction, amplification conditions and one-step qPCR procedure were described in detail in our previous reports [45-47]. For IHC analysis, TMA sections were incubated with a primary monoclonal mouse anti-Trop2antibody (1:200, Abcam). The IHC evaluation of Trop2 was defined in our previous reports [48-54].

\section{FACS analysis and immunofluorescence assay for Trop2Fab}

Both fluorescence-activated cell sorting (FACS) analysis and immunofluorescence assay were carried out on BxPC3, PL45, and NIH3T3 cell lines according to the methods that described in our previous researches [16, 22].

\section{Conjugation of Trop2Fab with DOX}

As shown in Figure 7, MAL-PEG-COOH was dissolved in dichloromethane to react with DOX under the activation by DCC/NHS to form the MAL-PEGDOX. Then MAL-PEG-DOX was added to the solution of Trop2Fab and TCEP in PBS, stirred at $37^{\circ} \mathrm{C}$ for $2 \mathrm{~h}$ to construct Trop2 Fab-DOX. 


\section{Detection of the release of DoX from Trop2 Fab-DOX}

The release rate of DOX from Trop2 Fab-DOX was detected by a spectrophotometer. Briefly, the Trop2 Fab-DOX was suspended in $1 \mathrm{~mL}$ of PBS in a filter bag, which was then placed in $300 \mathrm{~mL}$ medium of PBS $(\mathrm{pH} 7.2$ or $\mathrm{pH} 4.0)$ and shaken in an orbital shaker at $37^{\circ} \mathrm{C}$. The $1 \mathrm{~mL}$ medium was acquired and sampled for DOX concentration, and further analyzed for the accumulated release rate of DOX from Trop2 Fab-DOX.

\section{Cell ELISA and immunofluorescence assay for Trop2Fab-DOX}

For cell enzyme-linked immunosorbent assay (ELISA), BxPC3, PL45 and NIH3T3 cell lines were harvested in a logarithmic growth phase, and seeded on a 96 wells cell-culture plate at a cellular density of $10^{4}$ cells per $\mathrm{mL}$. After incubating and washing, the plate was blocked with $1 \%$ non-fat milk for $2 \mathrm{~h}$, followed by the addition of $50 \mu \mathrm{L}$ Trop2Fab-DOX and Trop2Fab with the same gradient effective-antibody concentrations from 0.625 to $10 \mu \mathrm{g} / \mathrm{mL}$ in triplicate wells. Then a goat antihuman Fab coupled with horseradish peroxidase (HRP) antibody was added $(1: 2000)$. After washing, observation was executed with TMB solution at room temperature for 30 min and stopped by $1 \mathrm{M} \mathrm{H}_{2} \mathrm{SO}_{4}$. The optical absorbance was measured at $450 \mathrm{~nm}$. For immunofluorescence assay, BxPC3 and PL45 cell lines were cultured in 6-well plates and immunofluorescence assay was performed according to the method described previously [16]. The unrelated Fab was used as a negative control in both assays.

\section{Route of Trop2Fab-DOX transported in PC cells}

BxPC3 and NIH3T3 cell lines were seeded into a 96-well cell culture plate at a density of $6 \times 10^{3}$ cells per well, and treated with Trop2Fab-DOX and DOX $(10 \mu \mathrm{g} / \mathrm{mL})$. The fluorescent signal of doxorubicin was
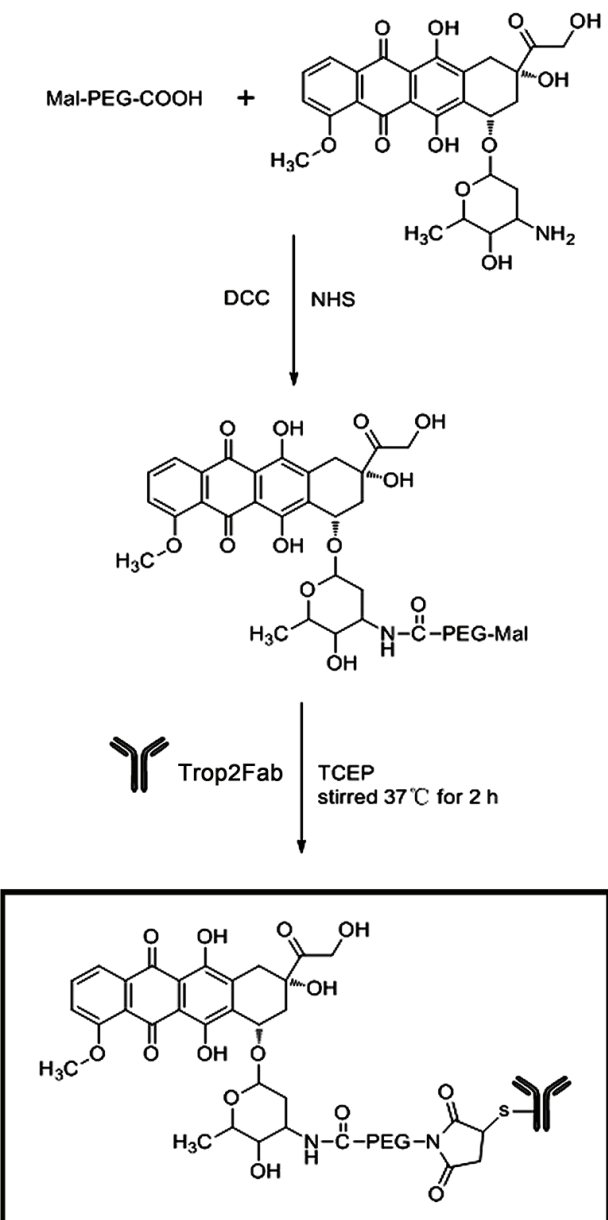

(Trop2Fab-DOX)

Figure 7: Conjugation of Trop2Fab fragment with DOX. MAL-PEG-COOH was dissolved in dichloromethane to react with DOX. The reaction was activated by DCC/NHS to form the MAL-PEG-DOX and an amide bond was created. Then MAL-PEG-DOX was added to the solution of Trop2Fab and TCEP in PBS, stirred at $37^{\circ} \mathrm{C}$ for $2 \mathrm{~h}$ to construct Trop2 Fab-DOX and a thioether bond was established. Trop2Fab-DOX was marked by a black frame. 
examined by fluorescence microscopy after treatment for $1 \mathrm{~h}, 2 \mathrm{~h}$ and $3 \mathrm{~h}$, respectively. The detailed protocol was described in our former studies $[16,22]$.

\section{MTT assay}

After incubating BxPC3, PL45 and NIH3T3 cell lines with various concentrations of Trop2Fab-DOX, DOX, Trop2Fab and unrelated Fab $(0.625-10 \mu \mathrm{g} / \mathrm{mL})$ for $24 \mathrm{~h}, 48 \mathrm{~h}$ and $72 \mathrm{~h}$, MTT assay was performed according to the methods described previously $[55,56]$. PBS was used as a negative control.

\section{Wound healing assay}

BxPC3, PL45 and NIH3T3 cell lines were treated with Trop2Fab-DOX, DOX, Trop2Fab and unrelated Fab with different concentrations $(0.625-10 \mu \mathrm{g} / \mathrm{mL})$ and wound healing assay was performed according to the method described previously [16]. PBS was used as a negative control.

\section{BxPC3 xenografts}

Four-week-old BALB/c nude mice with a body weight of 18-20 $\mathrm{g}$ were purchased from the SLAC Laboratory Animal (Shanghai, China), and they were kept under specific pathogen-free conditions. For BxPC3 xenograft establishment, all mice were injected with $5 \times 10^{6} / \mathrm{mL}$ BxPC3 cells subcutaneously in a volume of $0.1 \mathrm{~mL}$ into the flank. When tumors reached $100 \mathrm{~mm}^{3}$ after inoculation, the mice were randomly and evenly assigned to five groups ( 8 mice per group). Each mouse was injected intravenously on every two days with different drugs: group I: high concentration of DOX ( $2 \mathrm{mg} / \mathrm{kg})$; group II: low concentration of DOX (1 mg/ $\mathrm{kg}$ ); group III: Trop2Fab-DOX (containing $2 \mathrm{mg} / \mathrm{kg}$ of equivalent DOX); group IV: Trop2Fab $(6.52 \mathrm{mg} / \mathrm{kg}$, the same antibody concentration as Trop2Fab-DOX); group V: PBS as a negative control. After xenograft transplantation, mice bearing tumors were observed and tumor size was measured and recorded once every 2-3 days. Tumor volume was estimated according to the method described previously [16]. At the end of the treatment period (30th day), all mice were killed, and tumors were excised to determine tumor weight and perform IHC analysis. The animal studies were conducted in accordance with the Public Health Service Policy and approved by the Animal Care and Use Committee of Nanjing Medical University.

\section{Statistical analysis}

Trop2 expression was analyzed by the Wilcoxon signed-rank test. The significance of Trop2 expression on clinicopathological parameters of PC was analyzed by the $\chi^{2}$ test. Univariate and multivariate analyses were performed to identify the risk factors responsible for overall survival. The Kaplan-Meier method was used to evaluate the association between Trop2 expression and clinical outcomes in patients with PC. Quantitative data were expressed as means \pm standard deviation (s.d.), and analyzed by Variance Analysis and SNK-q test. The $p<0.05$ was considered statistically significant for a computed two-tailed probability. All the statistical analyses were completed with the SPSS version 18.0 (SPSS Inc., Chicago, IL, USA) and STATA version 12.0 (Stata Corporation, College Station, TX, USA).

\section{ACKNOWLEDGMENTS}

This work is supported by the grants from the National Natural Science Foundation for Youth of China (No.81301951); the Jiangsu Provincial Health International Exchange Program; the Six Talent Peaks Project of Jiangsu Province (2015-WSN-017); the Nanjing Science and Technology Development Program (No.201402055).

\section{Authors' contributions}

J.Z. and Y.M. designed the study; X.Y.W. and Q.T. collected the tissue samples; X.Y.W., F.Z., X.J.T. and N.X. executed the in vitro experiments; Y.M., C.J.W., H.L.Z., and D.W.Z. performed the in vivo experiments; N.X., L.X. and J.L. evaluated the IHC analysis; Y.M. completed the statistics and drafted the manuscript; J.Z. supervised the study. All authors read and approved the final manuscript.

\section{CONFLICTS OF INTEREST}

The authors declared that they have no competing interest.

\section{REFERENCES}

1. Siegel R, Ward E, Brawley O, Jemal A. Cancer statistics, 2011: the impact of eliminating socioeconomic and racial disparities on premature cancer deaths. CA Cancer J Clin. 2011; 61:212-236.

2. Wang X, Wang L, Mo Q, Dong Y, Wang G, Ji A. Changes of Th17/Treg cell and related cytokines in pancreatic cancer patients. Int J Clin Exp Pathol. 2015; 8:5702-5708.

3. Chen L, Fan J, Chen H, Meng Z, Chen Z, Wang P, Liu L. The IL-8/CXCR1 axis is associated with cancer stem cell-like properties and correlates with clinical prognosis in human pancreatic cancer cases. Sci Rep. 2014; 4:5911.

4. McGlynn LM, McCluney S, Jamieson NB, Thomson J, MacDonald AI, Oien K, Dickson EJ, Carter CR, McKay CJ, Shiels PG. SIRT3 \& SIRT7: Potential Novel Biomarkers for Determining Outcome in Pancreatic Cancer Patients. PLoS One. 2015; 10:e0131344. 
5. Wang Q, Ni Q, Wang X, Zhu H, Wang Z, Huang J. High expression of RAB27A and TP53 in pancreatic cancer predicts poor survival. Med Oncol. 2015; 32:372.

6. Guillaumond F, Iovanna JL, Vasseur S. Pancreatic tumor cell metabolism: focus on glycolysis and its connected metabolic pathways. Arch Biochem Biophys. 2014; 545:69-73.

7. Fornaro M, Dell'Arciprete R, Stella M, Bucci C, Nutini M, Capri MG, Alberti S. Cloning of the gene encoding Trop-2, a cell-surface glycoprotein expressed by human carcinomas. Int J Cancer. 1995; 62:610-618.

8. Chen R, Lu M, Wang J, Zhang D, Lin H, Zhu H, Zhang W, Xiong L, Ma J, Mao Y, Zhu J, Xu J. Increased expression of Trop2 correlates with poor survival in extranodal NK/T cell lymphoma, nasal type. Virchows Arch. 2013; 463:713-719.

9. Ripani E, Sacchetti A, Corda D, Alberti S. Human Trop-2 is a tumor-associated calcium signal transducer. Int J Cancer. 1998; 76:671-676.

10. Lin H, Huang JF, Qiu JR, Zhang HL, Tang XJ, Li H, Wang CJ, Wang ZC, Feng ZQ, Zhu J. Significantly upregulated TACSTD2 and Cyclin D1 correlate with poor prognosis of invasive ductal breast cancer. Exp Mol Pathol. 2013; 94:73-78.

11. Fang YJ, Lu ZH, Wang GQ, Pan ZZ, Zhou ZW, Yun JP, Zhang MF, Wan DS. Elevated expressions of MMP7, TROP2, and survivin are associated with survival, disease recurrence, and liver metastasis of colon cancer. Int $\mathrm{J}$ Colorectal Dis. 2009; 24:875-884.

12. Muhlmann G, Spizzo G, Gostner J, Zitt M, Maier H, Moser P, Gastl G, Zitt M, Muller HM, Margreiter R, Ofner D, Fong D. TROP2 expression as prognostic marker for gastric carcinoma. J Clin Pathol. 2009; 62:152-158.

13. Cubas R, Li M, Chen C, Yao Q. Trop2: a possible therapeutic target for late stage epithelial carcinomas. Biochim Biophys Acta. 2009; 1796:309-314.

14. Wang J, Day R, Dong Y, Weintraub SJ, Michel L. Identification of Trop-2 as an oncogene and an attractive therapeutic target in colon cancers. Mol Cancer Ther. 2008; 7:280-285.

15. Wu H, Xu H, Zhang S, Wang X, Zhu H, Zhang H, Zhu J, Huang J. Potential therapeutic target and independent prognostic marker of TROP2 in laryngeal squamous cell carcinoma. Head Neck. 2013; 35:1373-1378.

16. Lin H, Zhang H, Wang J, Lu M, Zheng F, Wang C, Tang X, Xu N, Chen R, Zhang D, Zhao P, Zhu J, Mao Y, et al. A novel human Fab antibody for Trop2 inhibits breast cancer growth in vitro and in vivo. Int J Cancer. 2014; 134:1239-1249.

17. Liu Z, Feng Z, Zhu X, Xu W, Zhu J, Zhang X, Fan Z, Ji G. Construction, expression, and characterization of an anti-tumor immunotoxin containing the human anti-c-Met single-chain antibody and PE38KDEL. Immunol Lett. 2013; 149:30-40

18. Ayla S, Seckin I, Tanriverdi G, Cengiz M, Eser M, Soner BC, Oktem G. Doxorubicin induced nephrotoxicity: protective effect of nicotinamide. Int J Cell Biol. 2011; 2011:390238.
19. Fulop Z, Gref R, Loftsson T. A permeation method for detection of self-aggregation of doxorubicin in aqueous environment. Int J Pharm. 2013; 454:559-561.

20. Matsudaira H, Asakura T, Aoki K, Searashi Y, Matsuura T, Nakajima H, Tajiri H, Ohkawa K. Target chemotherapy of anti-CD147 antibody-labeled liposome encapsulated GSHDXR conjugate on CD147 highly expressed carcinoma cells. Int J Oncol. 2010; 36:77-83.

21. Etrych T, Mrkvan T, Rihova B, Ulbrich K. Star-shaped immunoglobulin-containing HPMA-based conjugates with doxorubicin for cancer therapy. J Control Release. 2007; 122:31-38.

22. Chen X, Ding G, Gao Q, Sun J, Zhang Q, Du L, Qiu Z, Wang C, Zheng F, Sun B, Ni J, Feng Z, Zhu J. A human anti-c-Met Fab fragment conjugated with doxorubicin as targeted chemotherapy for hepatocellular carcinoma. PLoS One. 2013; 8:e63093.

23. Klute K, Nackos E, Tasaki S, Nguyen DP, Bander NH, Tagawa ST. Microtubule inhibitor-based antibody-drug conjugates for cancer therapy. Onco Targets Ther. 2014; 7:2227-2236.

24. Loganzo F, Tan X, Sung M, Jin G, Myers JS, Melamud E, Wang F, Diesl V, Follettie MT, Musto S, Lam MH, Hu W, Charati MB, et al. Tumor cells chronically treated with a trastuzumab-maytansinoid antibody-drug conjugate develop varied resistance mechanisms but respond to alternate treatments. Mol Cancer Ther. 2015; 14:952-963.

25. Leal M, Sapra P, Hurvitz SA, Senter P, Wahl A, Schutten M, Shah DK, Haddish-Berhane N, Kabbarah O. Antibodydrug conjugates: an emerging modality for the treatment of cancer. Ann N Y Acad Sci. 2014; 1321:41-54.

26. Panowksi S, Bhakta S, Raab H, Polakis P, Junutula JR. Sitespecific antibody drug conjugates for cancer therapy. MAbs. 2014; 6:34-45.

27. Ramsland PA, Hutchinson AT, Carter PJ. Therapeutic antibodies: Discovery, design and deployment. Mol Immunol. 2015.

28. Trerotola M, Jernigan DL, Liu Q, Siddiqui J, Fatatis A, Languino LR. Trop-2 promotes prostate cancer metastasis by modulating beta(1) integrin functions. Cancer Res. 2013; 73:3155-3167.

29. Fong D, Spizzo G, Gostner JM, Gastl G, Moser P, Krammel C, Gerhard S, Rasse M, Laimer K. TROP2: a novel prognostic marker in squamous cell carcinoma of the oral cavity. Mod Pathol. 2008; 21:186-191.

30. Bignotti E, Todeschini P, Calza S, Falchetti M, Ravanini M, Tassi RA, Ravaggi A, Bandiera E, Romani C, Zanotti L, Tognon G, Odicino FE, Facchetti F, et al. Trop-2 overexpression as an independent marker for poor overall survival in ovarian carcinoma patients. Eur J Cancer. 2010; 46:944-953.

31. van Rij CM, Frielink C, Goldenberg DM, Sharkey RM, Lutje S, McBride WJ, Oyen WJ, Boerman OC. Pretargeted Radioimmunotherapy of Prostate Cancer with an AntiTROP-2xAnti-HSG Bispecific Antibody and a (177) 
Lu-Labeled Peptide. Cancer Biother Radiopharm. 2014; 29:323-329.

32. Liu T, Tian J, Chen Z, Liang Y, Liu J, Liu S, Li H, Zhan J, Yang X. Anti-TROP2 conjugated hollow gold nanospheres as a novel nanostructure for targeted photothermal destruction of cervical cancer cells. Nanotechnology. 2014; 25:345103.

33. Stein R, Basu A, Goldenberg DM, Lloyd KO, Mattes MJ. Characterization of cluster 13: the epithelial/carcinoma antigen recognized by MAb RS7. Int J Cancer Suppl. 1994; 8:98-102.

34. Shih LB, Xuan H, Aninipot R, Stein R, Goldenberg DM. In vitro and in vivo reactivity of an internalizing antibody, RS7, with human breast cancer. Cancer Res. 1995; 55:5857s-5863s.

35. Govindan SV, Stein R, Qu Z, Chen S, Andrews P, Ma H, Hansen HJ, Griffiths GL, Horak ID, Goldenberg DM. Preclinical therapy of breast cancer with a radioiodinated humanized anti-EGP-1 monoclonal antibody: advantage of a residualizing iodine radiolabel. Breast Cancer Res Treat. 2004; 84:173-182.

36. Iyer U, Kadambi VJ. Antibody drug conjugates - Trojan horses in the war on cancer. J Pharmacol Toxicol Methods. 2011; 64:207-212.

37. Alley SC, Okeley NM, Senter PD. Antibody-drug conjugates: targeted drug delivery for cancer. Curr Opin Chem Biol. 2010; 14:529-537.

38. Cardillo TM, Govindan SV, Sharkey RM, Trisal P, Goldenberg DM. Humanized anti-Trop-2 IgG-SN-38 conjugate for effective treatment of diverse epithelial cancers: preclinical studies in human cancer xenograft models and monkeys. Clin Cancer Res. 2011; 17:3157-3169.

39. Friedrich L, Stangl S, Hahne H, Kuster B, Kohler P, Multhoff G, Skerra A. Bacterial production and functional characterization of the Fab fragment of the murine IgG1/ lambda monoclonal antibody cmHsp70.1, a reagent for tumour diagnostics. Protein Eng Des Sel. 2010; 23:161-168.

40. Zhang X, Xiao GG, Gao Y. Characterization of human colorectal cancer MDR1/P-gp Fab antibody. Scientific World Journal. 2013; 2013:716289.

41. Sharkey RM, van Rij CM, Karacay H, Rossi EA, Frielink C, Regino C, Cardillo TM, McBride WJ, Chang $\mathrm{CH}$, Boerman OC, Goldenberg DM. A new Tri-Fab bispecific antibody for pretargeting Trop-2-expressing epithelial cancers. J Nucl Med. 2012; 53:1625-1632.

42. Ohmachi T, Tanaka F, Mimori K, Inoue H, Yanaga K, Mori M. Clinical significance of TROP2 expression in colorectal cancer. Clin Cancer Res. 2006; 12:3057-3063.

43. Fong D, Moser P, Krammel C, Gostner JM, Margreiter R, Mitterer M, Gastl G, Spizzo G. High expression of TROP2 correlates with poor prognosis in pancreatic cancer. $\mathrm{Br} \mathrm{J}$ Cancer. 2008; 99:1290-1295.

44. Ryu B, Jones J, Blades NJ, Parmigiani G, Hollingsworth MA, Hruban RH, Kern SE. Relationships and differentially expressed genes among pancreatic cancers examined by large-scale serial analysis of gene expression. Cancer Res. 2002; 62:819-826.

45. Xu X, Tang X, Lu M, Tang Q, Zhang H, Zhu H, Xu N, Zhang D, Xiong L, Mao Y, Zhu J. Overexpression of MAGE-A9 predicts unfavorable outcome in breast cancer. Exp Mol Pathol. 2014; 97:579-584.

46. Gu X, Fu M, Ge Z, Zhan F, Ding Y, Ni H, Zhang W, Zhu Y, Tang X, Xiong L, Li J, Qiu L, Mao Y, et al. High expression of MAGE-A9 correlates with unfavorable survival in hepatocellular carcinoma. Sci Rep. 2014; 4:6625.

47. Mao Y, Zhang DW, Lin H, Xiong L, Liu Y, Li QD, Ma J, Cao Q, Chen RJ, Zhu J, Feng ZQ. Alpha B-crystallin is a new prognostic marker for laryngeal squamous cell carcinoma. J Exp Clin Cancer Res. 2012; 31:101.

48. Han L, Jiang B, Wu H, Zhang S, Lu X. Expression and prognostic value of MAGE-A9 in laryngeal squamous cell carcinoma. Int J Clin Exp Pathol. 2014; 7:6734-6742.

49. Xian H, Zhang H, Zhu H, Wang X, Tang X, Mao Y, Zhu J. High APRIL expression correlates with unfavourable survival of gastrointestinal stromal tumour. Pathology. 2014; 46:617-622.

50. Zhu H, Lu J, Wang X, Zhang H, Tang X, Zhu J, Mao Y. Upregulated ZO-1 correlates with favorable survival of gastrointestinal stromal tumor. Med Oncol. 2013; 30:631.

51. Ma J, Wang J, Fan W, Pu X, Zhang D, Fan C, Xiong L, Zhu $\mathrm{H}, \mathrm{Xu} \mathrm{N}$, Chen R, Liu S. Upregulated TIMP-1 correlates with poor prognosis of laryngeal squamous cell carcinoma. Int J Clin Exp Pathol. 2014; 7:246-254.

52. Ni S, Xu L, Huang J, Feng J, Zhu H, Wang G, Wang X. Increased ZO-1 expression predicts valuable prognosis in non-small cell lung cancer. Int J Clin Exp Pathol. 2013; 6:2887-2895.

53. Mao Y, Zhang DW, Zhu H, Lin H, Xiong L, Cao Q, Liu Y, Li QD, Xu JR, Xu LF, Chen RJ. LMP1 and LMP2A are potential prognostic markers of extranodal NK/T-cell lymphoma, nasal type (ENKTL). Diagn Pathol. 2012; $7: 178$.

54. Shi C, Yang X, Ni Y, Hou N, Xu L, Zhan F, Zhu H, Xiong L, Chen P. High Rab27A expression indicates favorable prognosis in CRC. Diagn Pathol. 2015; 10:68.

55. Chen R, Zhang D, Mao Y, Zhu J, Ming H, Wen J, Ma J, Cao Q, Lin H, Tang Q, Liang J, Feng Z. A human Fabbased immunoconjugate specific for the LMP1 extracellular domain inhibits nasopharyngeal carcinoma growth in vitro and in vivo. Mol Cancer Ther. 2012; 11:594-603.

56. Lin H, Mao Y, Zhang DW, Li H, Qiu JR, Zhu J, Chen RJ. Selection and characterization of human anti-MAGE-A1 $\mathrm{scFv}$ and immunotoxin. Anticancer Agents Med Chem. 2013; 13:1259-1266. 